\title{
Earnings Indicators under the Condition of Globalization
}

\author{
Anna Siekelova ${ }^{1, *}$, Ivana Podhorska ${ }^{1}$ \\ ${ }^{1}$ University of Zilina, Faculty of Operation and Economics of Transport and Communications, \\ Department of Economics, Univerzitna 1, 01026 Žilina, Slovak Republic.
}

\begin{abstract}
The paper is focused on the analysis of the influence of partial indicators on the selected top indicator, which is the earnings. The profit is the resulting effect of the enterprise's business activity and, at the same time, often the measure of whether the company is successful or not. Business performance data is one of the cornerstones for further corporate planning and decision making. It is necessary to point out the factors that influence the company's result. The main purpose of the contribution is the pyramidal breakdown of the economic performance indicator to identify the main factors influencing its change over the two-year reference period. The pyramidal breakdown of the economic result is complemented by the breakdown of the ROE indicator.
\end{abstract}

\section{Introduction}

Profit or loss is the result of the business activity of the company and often also a tool for measurement whether the company is successful or not. But many times it is influenced by the efforts of companies to reduce profits due to paying the lowest possible taxes. Making profits requires experienced managers who are able to achieve higher revenue than the costs they have incurred. The difference between the revenues and the costs incurred to obtain them is profit. This can be reasonably high, very high, low, zero or negative, resulting in loss. Therefore, in the professional practice we encounter many definitions of profit and profitability, which creates terminological chaos and you do not know which profit to use in what situations. Therefore, the theoretical basis of our article first focuses on the definition of profit, its classification and methodology of its calculation. The aim of our article in its practical part is the pyramidal decomposition of the economic result indicator profit in order to identify the main factors influencing its change in the monitored period of two years.

\section{Theoretical background}

In general, the economic result is most often calculated as the difference between all the revenues and all costs of an enterprise. In practice, two situations are most often observed. In case the company's revenues are higher than costs, the economic result is in the form of

* Corresponding author: anna.siekelova@fpedas.uniza.sk 
profit, otherwise the economic result is a loss. Depending on the costs taken into account in the calculation of profit, we distinguish the following forms of profit: $[1,2,3]$

- Economic Profit - reflects economic costs, such as the sum of explicit costs and implicit costs,

- Accounting Profit - reflects those costs that are reflected in the financial statements, exclusively explicit costs,

- Normal Profit - takes into account the opportunity costs and it is therefore a part of the economic cost in the form of implicit costs of production.

In practice, we distinguish the following categories of profits:

- Operating Income - which is quantified at three levels. On the first level, the trade margin is calculated as the difference between the revenue from the sale of goods and the cost of acquiring the goods sold; on the second level, we add production to the trading margin and subtract production consumption to provide added value, and finally add other operating income to the added value and subtract other operating costs.

- Financial Income - is the difference between financial income and financial expenses.

- Net Income or Earnings after Taxes (EAT) - is the sum of the economic result from economic activity and financial activity, minus the relevant taxes.

- Earnings Before Taxes (EBT) - is the sum of the economic result from economic activity and financial activity

Other profit / loss categories are:

- Earnings before Interest and Taxes (EBIT) - the sum of profit before taxes and interest expense.

- Earnings before Interest, Taxes, Depreciation and Amortization (EBITDA) - the sum of EBIT and depreciation of tangible and intangible fixed assets.

- Earnings before Depreciation and Amortization (EBDA)

- Earnings before Depreciation, Amortization and Taxes (EBDAT)

- Earnings before Depreciation, Amortization and Deferred Taxes (EBDAT)

- Earnings before Taxes and Stock Options (EBTSO)

- Earnings before Taxes, Depreciation, Amortization and Stock Options (EBITDASO)

- Earnings before Taxes, Depreciation and Amortization and Rents (EBTDAR)

- Earnings before Interest, Taxes and Research with Long-Term Character (EBITR)

- Net Operating Profit after Taxes (NOPAT) - is a company's potential cash earnings if its capitalization were unleveraged - that is, if it had no debt. NOPAT is frequently used in economic value added (EVA) calculations. NOPAT is a more accurate look at operating efficiency for leveraged companies, and it does not include the tax savings many companies get because of existing debt.

Profit is an important part of ratio indicators, mainly profitability indicators. Profit and profitability are in many professional works identified as decisive aspects of strategic and tactical decision making of the company. [4,5]

The aim of our article is a pyramidal decomposition of the profit indicator to identify the main factors influencing its change over a two-year period. 


\section{Methods and methodology}

As stated above, the goal of pyramidal decomposition is to quantify the impact of determining indicators, while quantification can be accomplished using several methods. Their use depends to some extent also on the relationships between the individual indicators of pyramidal decomposition, by means of which it is possible to decompose the peak indicator, in our case profit, by mathematical methods.

At the corporate level, it is usually sufficient to assume the following types of relationships: $[6,7,8]$

- additive relationships, where the relationship between sub-indicators is expressed by addition or subtraction;

- multiplicative relationships, where the relationship between sub-indicators is expressed by multiplication or division,

- combined relationships, where a combination of additive and multiplicative relationships is involved.

In additive relationships, quantifying the impact of determinants is simple. This is because absolute differences in factors are directly measurable.

$$
\begin{aligned}
& X_{0}=a_{0}+b_{0}+c_{0} \\
& X_{1}=a_{1}+b_{1}+c_{1}
\end{aligned}
$$

$X_{0} \quad$ is the basic (basic) value of the analysed indicator,

$X_{1} \quad$ is the common value of the analysed indicator,

$a_{0} ; b_{0} ; c_{0}$ are the basic values of the determinants,

$a_{1} ; b_{1} ; c_{1}$ are the common values of the determinants.

If all determinants differences are positive or negative then:

$$
\Delta X_{a}=\frac{\Delta a}{\Delta X} \cdot 100 \quad \Delta X_{b}=\frac{\Delta b}{\Delta X} \cdot 100 \quad \Delta X_{c}=\frac{\Delta c}{\Delta X} \cdot 100
$$

We characterize the percentage influence of different values of individual determinants on the synthetic indicator. If there are both positive and negative differences then:

$$
\Delta X_{a}=\frac{\Delta a}{X_{0}} .100 \quad \Delta X_{b}=\frac{-\Delta b}{X_{0}} .100 \quad \Delta X_{c}=\frac{\Delta c}{X_{0}} .100
$$

This is how much $X_{1}$ is lower / higher than $X_{0}$ because of the different values of the individual determinants.

In multiplicative relation of determinants, where eg. $X=a \cdot b \cdot c$, the situation is more complicated in quantifying the impact of change of individual determinants.

This is because: $[9,10]$

- the absolute difference between the different analytical determinants (factors) gives rise to a different difference of the (synthetic) indicator analyzed;

- given given absolute differences of individual analytical determinants (factors), the absolute difference of the analyzed (synthetic) indicator varies depending on the magnitude of the actual values of the indicators.

It follows from the above that in the multiplicative linkages of agents their absolute differences are not symmetrical, it means:

$$
\Delta X \neq \Delta a \cdot \Delta b \cdot \Delta c
$$


Various methods are used for quantification. The best known include: [11,12,13]

- chain-substitution method

$$
\begin{aligned}
& \Delta X_{a}=\left(a_{1}-a_{0}\right) \cdot b_{0} \cdot c_{0} \rightarrow \Delta X_{a}=\Delta a \cdot b_{0} \cdot c_{0} \\
& \Delta X_{b}=a_{1} \cdot\left(b_{1}-b_{0}\right) \cdot c_{0} \rightarrow \Delta X_{b}=a_{1} \cdot \Delta b \cdot c_{0} \\
& \Delta X_{c}=a_{1} \cdot b_{1} \cdot\left(c_{1}-c_{0}\right) \rightarrow \Delta X_{c}=a_{1} \cdot b_{1} \cdot \Delta
\end{aligned}
$$

- logarithmic method

$$
\Delta X_{a ; b ; c}=\Delta X \cdot \frac{\log \frac{a_{1} ; b_{1} ; c_{1}}{a_{0} ; b_{0} ; c_{0}}}{\log \frac{X_{1}}{X_{0}}}
$$

- functional method

$$
\begin{aligned}
& A=\frac{\Delta a}{a_{0}}=\frac{a_{1}}{a_{0}}-1 \\
& B=\frac{\Delta b}{b_{0}}=\frac{b_{1}}{b_{0}}-1 \\
& C=\frac{\Delta c}{c_{0}}=\frac{c_{1}}{c_{0}}-1 \\
& \Delta X_{a}=X_{0} \cdot A\left[1+\frac{B+C}{2}+\frac{B \cdot C}{3}\right] \\
& \Delta X_{b}=X_{0} \cdot B\left[1+\frac{A+C}{2}+\frac{A \cdot C}{3}\right] \quad \Delta X=\Delta X_{a}+\Delta X_{b}+\Delta X_{c} \\
& \Delta X_{C}=X_{0} \cdot C\left[1+\frac{B+A}{2}+\frac{B \cdot A}{3}\right]
\end{aligned}
$$

\section{Results and discussion}

The decomposition of profit / loss is a type of decomposition where the synthetic indicator is given by additive relations. In view of this, we did not have to apply any specific method of quantifying the effects of changes in partial indicators on the synthetic indicator to determine the year-on-year changes in indicators and the effects of partial indicators on the synthetic indicator.

In the year-on-year comparison 2018/2017, earnings indicator for the current post-tax period increased by $133.78 \%$, which represented an increase of $€ 202,556$ in absolute terms.

Subsequently, we took into account the effects of partial economic results 'gross' and the quantified tax liability. On this basis, we found that the year-on-year increase in profit from ordinary activities after tax by $133.75 \%(+€ 202,525)$ was positively influenced by the increase in profit from ordinary activities before tax. If the condition 'ceteris paribus' were to be respected, gross profit from ordinary activities would increase the profit from ordinary activities after tax by EUR 178 873, which represents a 88,32\% share of its total change. The tax on ordinary activities, as another partial indicator, also affected the earnings on 
ordinary activities after tax. Since the company's normal tax liability decreased year-onyear, namely by $€ 23,652$, a development that can be considered positive from the point of view of the synthetic indicator - normal operating profit after tax. I under otherwise unchanged conditions, a decrease in the tax liability from ordinary activities would reduce the value of the synthetic indicator by $€ 23,652$, which represents approximately $11.68 \%$ of its total change. Furthermore, we also took into account changes in partial economic results within the ordinary activities - economic activities and financial activities. Earnings from economic activity increased year-on-year by $€ 208,800$, which also represents an absolute positive impact on the change in GVA from ordinary activities after tax, in relative terms it represents a $103.08 \%$ share in the total change in the monitored synthetic indicator. The earnings of financial activity was the only one that had a negative impact on the synthetic indicator, as the loss from this activity exceeded the year-on-year increase by $€ 29,927$. This also represents the value by which, under otherwise unchanged conditions, this indicator would reduce the company's total net profit; in relative terms it is a negative share of about $11.68 \%$ of the change.

Return on equity reflects the ability of an enterprise to capitalize on its equity. Through the pyramidal decomposition of the synthetic indicator of return on equity (ROE), we tried to identify the causes of its values in the selected period as accurately as possible.

There can be three types of relationships between a partial and a synthetic indicator additive (synthetic indicator is expressed by the sum or difference of partial indicators), multiplicative (synthetic indicator is expressed by the product or ratio of partial indicators) and combined. Decomposition of return on equity (ROE) is determined by multiplicative relations of partial indicators (first, second branch of decomposition), but also by additive or resp. combined bonds (other decomposition branches).

In the reporting period $2017 / 2018$, return on equity decreased by $€ 0.03$. The amount of return on equity is, of course, influenced mainly by the amount of net profit and equity, and we assume that if the amount of net profit increases, the return on equity increases and if the amount of equity increases the return on equity decreases. Net profit increased year-onyear by $€ 4,496,960$. The value of equity increased by $€ 707,596$ in the period under review, which negatively influenced the development of return on equity. To determine the impact of these indicators on the synthetic ROE indicator, a logarithmic method was used to determine that the effect of the EAT change on the change in the synthetic ROE indicator is $35.10 \%$ and that of the change in equity is $143.33 \%$, but unlike the impact net profit is affected by the synthetic indicator negatively.

Subsequently, we took into account the effect of the first branch of DuPont's decomposition, which is the product of the return on assets and the leverage. Based on this, we found that the change in ROE $€ 0.03$ was positively influenced by increasing financial leverage, the impact of this change on the synthetic ROE indicator was $77.80 \%$, this change was negatively affected by a decrease in return on assets, while the impact of this change on ROE is $192.25 \%$.

One branch further, we also analyzed the effect of partial indicators on the return on assets, where we considered this indicator to be synthetic. Return on sales influenced this indicator negatively as the value of this indicator decreased and this influence was $64.69 \%$ (as the value of this indicator increased) and the turnover of assets also decreased year-onyear, which also affected the return on assets also negatively. the synthetic indicator of return on assets was $30.01 \%$.

In the analysis of the influence of partial indicators on the synthetic indicator we used in all cases logarithmic method. We only considered revenue from primary activity as revenue. 


\section{Conclusion}

From the point of view of the right direction of the company it is important to know the financial health of the company and to conduct financial analyzes regularly. The main objective of the financial analysis is to give a true picture of the effective management of the company. The evaluation of the company results in important knowledge about how the assets in the company are used, what is the solvency of the company, but also its business partners, and what is the return on equity. According to neoclassical theory, [14,15] profit is considered to be the main goal of the enterprise. The aim of our contribution was a pyramidal decomposition of the economic result indicator in order to identify the main factors influencing its change in the monitored period of two years. The pyramidal decomposition of the economic result was supplemented by the decomposition of the ROE indicator.

This research was financially supported by the Slovak Research and Development Agency - Grant NO. APVV-17-0546 Variant Comprehensive Model of Earnings Management in Conditions of The Slovak Republic as an Essential Instrument of Market Uncertainty Reduction.

\section{References}

1. K. Valaskova, K. Kramarova, B. Kollar, Theoretical Aspects of a model of credit risk determination- Credit risk. Advances in Education Research 81, 401-406 (2015).

2. K. Valaskova, V. Bartosova, P. Kubala, Behavioural Aspects of the Financial Decision-Making. Organizacija 52, 22-32 (2019).

3. K. Valaskova, K. Kramarova, Analysis of market performance in the European Union and Slovakia. Proceedings of the 15th International Scientific Conference Globalization and its Socio-Economic Consequences. Rajecke Teplice, Slovakia, 834844 (2015).

4. Ch. Bolton, V. Machova, M. Kovacova, K. Valaskova, The Power of HumanMachine Collaboration: Artificial Intelligence, Business Automation, and the Smart Economy. Economics, Management, and Financial Markets 13, 51-56 (2018).

5. A. Fielden, M. Grupac, P. Adamko, How Users Validate the Information They Encounter on Digital Content Platforms: The Production and Proliferation of Fake Social Media News, the Likelihood of Consumer Exposure, and Online Deceptions. Geopolitics, History, and International Relations 10, 51-57 (2018).

6. R. Sadaf, J. Olah, J. Popp, D. Mate, An Investigation of the Influence of the Worldwide Governance and Competitiveness on Accounting Fraud Cases: A CrossCountry Perspective. Sustainability 10, 1-11 (2018).

7. A. Kargol-Wasiluk, A. Wildowicz-Giegiel, The quality of public finance in the light of tfiscal governance concept:implications for the European Union countries. Equulibrium - Quarterly Journal of Economics and Economic Policy 13, 411-426 (2018).

8. T. Conley, S. Goncalves, Ch. Hansen, Inference with Dependent Data in Accounting and Finance Applications. Journal of Accounting Research 56, 4, 1139-1203 (2018)

9. P. Liskowsky, M. Minnis, A. Sutherland, Economic Growth and Financial Statement Verification. Journal of Accounting Reserach 55, 4, 745-794 (2017). 
10. D. Godsell, M. Welker, N. Zhang, Earnings Management During Antidumpling Investigations in Europe: Sample-Wide and Cross-Sectional Evidence. Journal of Accounting Research 55, 2, 407-457 (2017).

11. J.-N. Barrot, E. Loualiche, J. Sauvagnat, The Globalization Risk Premium. Journal of Finance 74, 5, 2391-2439 (2019).

12. F. Restrepo, L. Cardona-Sosa, P. E. Strahan, Funding Liquidity without Banks : Evidence from a Shock to the Cost of Very Short-Term Debt. Journal of Finance 74, 6, 2875-2914 (2019).

13. C. K. Lau, The economic consequences of business sustainability initiatives, Asian Pacific Journal of Management 36, 937-970 (2019).

14. J. N. Barrot, E. Loualiche, J. Sauvagnat, The Globalization Risk Premium, Journal of Finance 74, 2391-2439 (2019).

15. J. Hromcova, P. Agnese, Globalization, welfare, and the attitudes toward higher education, Economic Modelling 81, 503-517 (2019). 